\title{
A releitura do Mito de Don Juan por Leopoldo Marechal em uma versão fantástica do teatro argentino
}

\author{
Maira Angélica Pandolfi \\ Universidade Estadual Paulista "Júlio de Mesquita Filho" (UNESP), Assis, São Paulo, Brasil \\ mairapan@gmail.com
}

DOI: http://dx.doi.org/10.21165/el.v46i3.1753

\begin{abstract}
Resumo
Pretende-se realizar uma análise da releitura do Mito de Don Juan pelo escritor argentino Leopoldo Marechal, com ênfase em seus elementos mítico-simbólicos. Essa peça, de publicação póstuma, foi finalizada em medos da década de 60. Os elementos fantasmagóricos constituem uma forte presença na escritura dramática e permitem a sua inserção na tradição literária do teatro fantástico europeu e argentino. A dialética entre o local e o universal na peça permite a reunião de mitos e crenças europeias com aquelas presentes na cultura e no folclore argentino, associados à teologia católica e à vertente política peronista defendida por seu autor. Dentre esses elementos destacam-se a figueira, o rio, o duende, el gavilán, assim como personagens e lugares referenciais da pampa argentina, e a mágica "Noche de San Juan". A trindade cristã é uma presença estrutural e semântica constante na peça, profetizando o destino final do protagonista e sua redenção.
\end{abstract}

Palavras-chave: mito de Don Juan; teatro argentino; Leopoldo Marechal.

\section{La relectura del Mito de Don Juan por Leopoldo Marechal en una versión fantástica del teatro argentino}

\section{Resumen}

Se busca realizar un análisis de la relectura del Mito de Don Juan por el escritor argentino Leopoldo Marechal, con énfasis en sus elementos mítico-simbólicos. El teatro, de publicación póstuma, fue finalizado alrededor de la década de los 60 . La fantasmagoria es fuertemente señalada en la escritura dramática y contribuye a que la obra se inserte en la tradición del teatro fantástico europeo y argentino. La dialéctica entre el local y el universal permite la unión entre los mitos y las creencias europeas con los de la cultura local, asociados a la teología católica y a la vertiente política del peronismo defendida por su autor. Entre los elementos se confiere destaque a la figuera, al río, al duende, al gavilán, así como a los personajes y espacios referenciales de la pampa argentina y a la mágica "Noche de San Juan". La trinidad cristiana es una presencia estructural y semántica recurrente en el drama, profetizando el destino final de su protagonista y su redención.

Palabras-clave: mito de Don Juan; teatro argentino; Leopoldo Marechal.

Leopoldo Marechal (1900-1970) foi um destacado poeta, romancista e dramaturgo argentino que participou ativamente das polêmicas literárias sustentadas pelos integrantes de uma das revistas mais importantes de sua geração: a revista Martín Fierro (1924-1927). Neste artigo, pretende-se apresentar algumas reflexões críticas sobre a releitura marechaliana do mito de Don Juan em uma de suas peças de teatro. Em um estudo crítico sobre a obra do escritor argentino, Graciela Maturo (1999) sugere que o drama Don Juan, de caráter metafísico-teológico e publicação póstuma (1978), tenha sido escrito em meados da década de 60. 
Maria Rosa Lojo (1997) afirma que Leopoldo Marechal e Jorge Luis Borges pertenceram à brilhante geração dos anos vinte, conhecida como a geração do "martinfierrismo". Para a estudiosa, essa geração, herdeira das vanguardas europeias, promoveu uma verdadeira revolução estética baseada na "eficiência da imagem, na metáfora deslumbrante que aproxima ideias distantes, assim como a conjunção inédita entre o universal e o crioulo, entre o rural e o urbano" (LOJO, 1997, p. 95, tradução nossa $)^{1}$. Contudo, apesar das iniciais coincidências literárias entre os dois autores "martinfierristas", ambos caminharam, segundo Secchi (2014), por veredas opostas, acentuadas principalmente por divergências políticas. Adepto do catolicismo e do peronismo, Leopoldo Marechal sofreu duras críticas dos escritores agrupados em torno da revista Sur, dirigida por Victoria Ocampo, e sobre os quais Borges exerceu grande influência. $\mathrm{O}$ antiperonismo de todos favoreceu a progressiva marginalização do autor de Don Juan (SECCHI, 2014). Essa nuvem escura que prontamente cobriu o horizonte de Leopoldo Marechal apenas seria dissipada em 1949 quando o jovem escritor Julio Cortázar teceu vários elogios, publicados na revista Realidad (a revista rival de Sur), ao seu romance mais conhecido, Adán Buenosayres.

Em 1939 foi publicada a primeira edição, em livro, do ensaio "Descenso y ascenso del alma por la belleza". Esse texto foi uma escritura que Leopoldo Marechal trabalhou por mais de trinta anos (1933, 1939, 1950 e 1965). Na última versão, que incorpora a reflexão estético-metafísica do autor nos últimos trinta anos, este afirma que o universo é um grande livro redigido pelo Criador e que pode ser lido pelo homem, conectando, assim, todo ser vivente ao divino. Segundo Secchi (2014), é em Dante que Marechal encontrou a chave para a sua proposta de escritura e leitura do mundo, buscando no poeta florentino os quatro sentidos de interpretação de uma obra. O primeiro seria o sentido literal, que comporta a dimensão estética e expressiva; o segundo o alegórico, que consiste na força metafórica; o terceiro é o moral e seu poder de transformação; o quarto sentido é o anagógico, ou seja, a religação do indivíduo com Deus. Seriam estas as chaves de interpretação da obra de Marechal cuja escritura, densamente trabalhada, é construída sobre várias camadas que se sobrepõem. Para Alfredo Rubione (2005), uma leitura atenta de Don Juan não pode dispensar essas chaves de interpretação expostas no referido ensaio estético-metafísico, visto que sua escritura não foi motivada simplesmente pelo desejo de revisitação ao mito donjuanesco, mas, acima de tudo, pelo anseio de encontrar uma via de exposição dramática de suas convicções sobre a alma, a beleza, o amor, o pecado, etc. Em razão disso, o herói donjuanesco de Leopoldo Marechal representa, em certa medida, essa alma inquieta, sedenta e perdida na multiplicidade de mulheres e imagens imperfeitas.

\section{Don Juan, de Leopoldo Marechal}

O drama Don Juan é complexo e está orientado por um simbolismo que vincula diretamente o autor à sua conversão religiosa, fundamentada no catolicismo. Inspirado também por uma hermenêutica platônica, os diálogos presentes na obra de Leopoldo Marechal estão sempre carregados de um sentimento transcendente, oculto sob a camada explícita do texto. Desse modo, a temática amorosa em seu Don Juan converge para o encontro com a beleza e a unidade. Em razão disso, a mulher surge como figura central,

\footnotetext{
${ }^{1}$ eficacia de la imagen, en la metáfora deslumbrante que acerca lejanías, y en la conjunción inédita de lo universal y lo criollo, de lo rural y de lo urbano.
} 
pois sobre ela recai a função de conduzir a alma peregrina e reduzir suas múltiplas experiências, até fundi-la a uma unidade. Ao tratar da dimensão filosófica na obra de Marechal, Secchi (2014) destaca a versão de 1965 do ensaio "Descenso y Ascenso del alma por la belleza", no qual o autor resume suas ideias estético-metafísicas. Nessa versão, consta novamente a referência a Platão quando o autor expõe o discurso de Diotima, pertencente ao Banquete. Para Diotima, amar o belo é o primeiro passo na busca de algo bom. Esse objetivo somente pode ser atingido pela intermediação de Eros; força conciliadora dos opostos. Assim, complementa Secchi (2014, p. 63, tradução nossa), "Eros é esse profundo desejo que leva cada um a buscar a outra metade que lhe corresponde, a fim de recuperar a totalidade perdida"

Como simbologia-chave prevalece na obra, em diversos aspectos, uma tríade: "Tres Marias"; "tres ventanas"; "tres brujas"; "tres corazones". São três, também, as invariantes que, segundo Jean Rousset (1985), estruturam o cenário donjuanesco permanente: o morto, o grupo feminino e o herói. Essas três dimensões, assim como as inumeráveis combinações possíveis no interior de cada uma delas, vão assegurar a mobilidade, a vitalidade e a renovação do roteiro mítico-literário de Don Juan em diferentes épocas e literaturas.

Desde o Burlador de Sevilla y Convidado de piedra (1630), de Tirso de Molina, a peça principal que conecta todas as dimensões da tríade referida é a filha do Comendador (ou do morto), Dona Ana. Na peça de Leopoldo Marechal, a filha do morto (ou da morte) é Dona Inés e sua missão consistirá não mais em prolongar a presença da morte ou da vingança, mas, ao contrário, contribuir para a redenção do herói no final da tragédia. Desaparece, assim, a estátua vingadora que retorna do mundo dos mortos para punir o burlador e, em seu lugar, ganha corpo a figura da redentora Inés, que resgatará Don Juan do "descenso" (das profundezas da Salamanca) para propiciar-lhe o "ascenso" e preservar, assim, sua memória. Nessa versão feminina do sublime, Inés se converte na representação da mulher-canção e do amor transcendental, fundamentado no platonismo de Leopoldo Marechal. Esse aspecto propicia uma nova releitura, de caráter religioso, do mito donjuanesco. A dimensão religiosa, que nasce na obra matriz, a de Tirso de Molina, geralmente desaparece ou é minimizada em diversas versões modernas que suprimem a estátua de pedra. Contudo, Leopoldo resgata essa vertente e a revitaliza a seu modo.

Don Juan é alvo de perseguição pelos habitantes de um pequeno povoado da província argentina de Santa Fé, onde ele seduziu e levou à ruína três raparigas, aludidas sempre pela expressão "Três Marias". Essa imagem reúne as mulheres seduzidas por ele sob o signo de uma constelação estrelar. As "Três Marias" são as três vítimas de Don Juan e representam a força de sua ação maléfica, que é sentida pela população do pequeno povoado e transformada em sede de vingança. As três bruxas do início do drama representam o contraponto com as Três Marias, pois não são vítimas dele.

Nesse coro, destacam-se uma bruxa profética, que antecipa metaforicamente o episódio final, e também aquela que o conduzirá à Salamanca infernal: Aymé. Esta mulher representa o "descenso" pelo qual toda alma peregrina precisa passar até atingir o "ascenso", que será conduzido por Inés, a "mulher-canção", ideal do eterno feminino almejado pelo herói. A bruxa profética afirma categoricamente a Aymé que Don Juan ainda irá notá-la e, desde sua conversa inicial com ele, esta mesma bruxa reitera a profecia

\footnotetext{
${ }^{2}$ Eros es ese profundo deseo que empuja a cada uno a buscar la outra mitad que le corresponde para recobrar la totalidade que se ha perdido.
} 
do rio: ¡Hoy llegarás a Santa Fe, paisano! ¡Hoy llegarás, aunque no quieras!’. A bruxa lhe diz, ainda, que atravessará o rio por causa de "tres ventanas que se han cerrado. Por dos corazones rotos, y uno más que se pudre bajo latierra" (MARECHAL, 2005, p. 42). Don Juan não compreende sua linguagem simbólica, assim como a afirmação incisiva de que ele atravessará o rio de qualquer maneira. A profecia anunciada pela bruxa, assinalando o percurso inevitável das águas ao "gavilán", revela, na releitura do autor argentino, a possibilidade de regeneração do maléfico sedutor.

A simbologia do rio se une a outros tópicos cristãos centrais no drama como a noite de San Juan (Noite de São João Batista) e a figueira, contribuindo para a criação de uma sequência simbólica que converge para o ritual do batismo e a morte iniciática do herói. De acordo com Mircea Eliade (1979, p. 148) "em qualquer conjunto religioso em que se encontrem, as águas conservam inicialmente a sua função: elas desintegram, anulam as formas, 'lavam os pecados', simultaneamente purificadoras e regeneradoras". A noite de São João também está relacionada a esse sintagma cristão das águas batismais embora conserve, paradoxalmente, o símbolo do fogo como ícone central de seu ritual festivo, mantendo acesa a memória de sua origem pagã, quando as culturas pré-cristãs comemoravam o solstício de verão no hemisfério sul e o solstício de inverno no hemisfério norte. Essa celebração comporta um fundo metafísico que, em suas origens, esteve relacionado ao poder transformador do astro rei, o sol, sobre a vida do homem. $\mathrm{O}$ solstício solar, que resulta no dia mais longo do ano, era considerado pelos antigos gregos como um rito de conexão com os deuses do Olimpo, denominado de "Porta dos homens". Consistia, portanto, em um momento de introspecção e meditação sobre as experiências vividas, rendendo homenagens, sobretudo, a Apolo, o deus solar invocado pelo fogo que, assim como a água, é um elemento purificador. A mitologia romana, contudo, associa esse ritual às duas caras de Jano que simbolizam a transição do passado ao futuro, da vida à morte $\mathrm{e}$ desta ao renascimento, compondo um ciclo.

O Don Juan de Leopoldo Marechal é esse porta-voz do duplo, das duas caras de Jano, pois se instaura entre o seu passado (convertido em lenda) e as profecias sobre o seu futuro. Contudo, o principal argumento da peça é o enfrentamento do sedutor com seu passado lendário e sua posterior libertação e renovação:

Don Juan: ¿Quién es Leonor?

Inés: - Mi nodriza, la negra.

Don Juan: -¿Y ella qué sabe?

Inés:-Que usted ha dormido bajo una higuera, la noche de San Juan; que ha visto florecer la higuera y que, por eso, anda como endemoniado.

Don Juan: $-¿$ Usted lo cree?

Inés: - No sé qué pensar. El mundo está lleno de razones oscuras; y la desgracia llega de cualquier parte, como el viento. "Reza por los embrujados", me decía mi madre (MARECHAL, 2005, p. 54).

Em diversas culturas, o advento do solstício de verão abrange uma dimensão mágica, uma abertura de portas invisíveis que levam a uma via transcendente. Na cultura celta, celebrava-se, no dia do solstício, a liberação das forças da natureza, acentuando-se 
o poder de algumas plantas medicinais e invocação de todos os seus elementos como forma de pedir benção aos enamorados e à fertilidade das mulheres. Na cultura asteca, eram celebrados cultos em prol das colheitas e da saúde. Na tradição cristã, o solstício também está relacionado à crença na fertilidade feminina, uma vez que as histórias bíblicas tratam de um anjo que revelou a Zacarias que sua mulher, considerada estéril, daria luz a um filho. Como retribuição a essa benção, conta-se que Zacarias acendeu uma grande fogueira, símbolo de purificação. A igreja católica passou a comemorar na data de 24 de junho o dia de São João Batista; o porta-voz de um futuro promissor, da vinda de um novo sol, Jesus, cujo caminho deveria ser preparado por seu antecessor, João Batista.

Fundamentado nos postulados do arcebispo Isidoro de Sevilha, Leopoldo Marechal expressa em seu "Capítulo V - El descenso" (que forma parte de seu tratado estético-filosófico "Descenso y ascenso del alma por la beleza") que a alma desce até as criaturas para atender a um chamado. Somente atendem a esse chamado porque são atraídas pela beleza que, por sua vez, é a expressão concreta da verdade e do bem. A alma peregrina atende a este chamado porque sua vocação é a felicidade. Esses postulados metafísicos e religiosos que embasam a estética de Leopoldo Marechal foram representados em sua trama ficcional por meio da condição errante de Don Juan, alma fragmentada, peregrina e perdida em seu labirinto de ilusões que, ao final, encontra um veículo de ascensão que o conduzirá a uma unidade. Inês é a personificação literária dessa ponte para a transcendência do herói e, por isso, ela encarna um símbolo universal e místico: a linguagem musical:

Don Juan: - ¡Es la pura verdad! Oí una canción; y salíen su busca, para ver si la canción tenía una cara.

Inés: - ¿La tenía?

Don Juan: - La tiene.

Inés: - Si la canción tu viera un semblante, no sería como el mío.

Don Juan: - ¿Por que no? Todo canta en usted, ¿lo sabía? Usted cree que dejó de cantar al verme; pero sigue cantando, de pies a cabeça.

Inés: - Si la canción tu viese una cara, se parecía más a la de los ángeles.

Don Juan: - ¿Usted ha visto a los ángeles?

Inés: - No, señor. ¿Y usted?

Don Juan: - Yo tampoco. (La mira largamente). Es decir, ahora no estoy seguro (MARECHAL, 2005, p. 53).

O chamado também não passa de ilusão, pois, segundo nos explica Marechal (2005) em seu ensaio, há uma imensa desproporção entre o bem relativo que lhe oferece a criatura (pensemos aqui no caso de Inês, a mulher-anjo-canção) e o bem absoluto que almeja a alma humana (personificada na ficção pelo mundano Don Juan e sua sede insaciável). Acrescenta-se a essa questão o fato de que Leopoldo Marechal se inspira em Dante Alighieri e sua concepção de Intellecto D'Amore; um perfeito paradoxo para ele, visto que o intelecto está ligado à faculdade cognoscitiva enquanto o amor se relaciona à 
faculdade instintiva e possessiva da vontade. Em vez desse duplo postulado, o autor argentino opta por uma forma de conhecimento mais voltada à unidade, sua busca obsessiva, preferindo o que ele denomina de a "Inteligência da Beleza", que pressupõe o amor recíproco. O amante se converte no ser amado, abandonando-se de si mesmo para assumir a forma daquilo que se ama, segundo a pregação de Santo Agostinho. Mas essa lógica parece não se aplicar à personagem Don Juan em virtude da desproporção que há entre sua "sede" gigantesca e o pequeno oásis que lhe oferecem. A metáfora da sede e do rio, que serve para iluminar a metafísica proposta por Leopoldo Marechal no referido ensaio, resulta em uma repetição de imagens na configuração de seu Don Juan. Quando os velhos da vila comentam com ele o fim trágico de uma de suas vítimas, morta como uma planta sem água, Don Juan complementa: "Sí. Sí. Una gran sed: eso fue toda ella" (MARECHAL, 2005, p. 46). Como consequência desse descompasso, a alma donjuanesca está sempre dividida entre a multiplicidade de seus amores, impedindo que se concretize sua vocação à unidade. Deter-se é aprisionar-se, assim, surgem inúmeros símbolos de liberdade encarnados pela figura de Don Juan: el gavilán, el viento, el duende, el redomón oscuro. $\mathrm{O}$ polo contrário é a unidade, simbolizada pela figueira florida, e representada por Inés, em contraponto à flor murcha de seus amores frustrados: "Porque usted ha sido para mí como la higuera que sólo florece una noche" (MARECHAL, 2005, p. 68).

Por influência de sua visão religiosa, Leopoldo Marechal não apresenta uma visão pessimista do homem como um anjo caído, irreparável, mas uma visão católica de sua dignidade por acreditar que o humano possui também a face do divino. Assim sendo, o mundo é como um livro a ser lido ou um enigma a ser decifrado onde o homem se perde para depois se encontrar e transcender.

Don Juan, de Leopoldo Marechal, possui matizes bem marcados que o alinham à tradição do herói romântico de algumas versões donjuanescas, sobretudo, a versão espanhola de José Zorrilla. No Don Juan Tenorio (1844), de Zorilla, o herói, assim como na versão criolla de Marechal, defronta-se com suas próprias culpas. O espanhol reencontra-se com os fantasmas de suas vítimas em forma de estátuas, que aludem, metaforicamente, à sua consciência culpada. Na versão argentina, a metáfora de suas culpas não é representada pelas estátuas, mas pelo coro de vozes femininas de suas vítimas que o atormentam na "casa que grita". Esta casa escura, e que grita, pode ser lida também como metáfora da consciência culpada do herói. Para Bachelard (1978), a casa pode ser um símbolo dos espaços habitados interiormente e até representar um espaço onírico. $\mathrm{Na}$ análise em questão, trata-se de um espaço que em vez de significar refúgio e acolhimento, à semelhança do ventre materno, torna-se um verdadeiro pesadelo, do qual Don Juan precisa se libertar. Essa cena, onde ele surge atormentado por diversas vozes que gritam no interior de sua casa, antecede o encontro com Inês, que invade o espaço atormentado a partir do simples gesto de Don Juan de abrir as janelas para deixar entrar a luz. Com a luz ouve-se uma doce melodia, cantada por Inês. A casa de seu devaneio é a casa de seu passado, de suas culpas, das quais ele precisa se libertar para transcender. Entre o peso do passado (representado pelas Três Marias) e o anseio do futuro (representado por Inês) encontra-se um herói atormentado. Essa nova faceta consiste na morte do mito barroco, que é caracterizado pela inconstância do herói e seu eterno movimento, a fim de dar preferência ao tempo permanente e não mais ao instante fugaz. $\mathrm{O}$ desejo de aquietar-se, de permanecer, revela-se metaforicamente em suas palavras a 
Inés que, supersticiosamente, o julga por ter dormido embaixo da figueira na noite de São João, atraindo maus espíritos:

Don Juan (en un dolorido crescendo). Lo malo es apartarse de la higuera, con la loca visión de la dicha; ensillar tormentosos caballos e irse al norte, al sur, al este y al oeste, para buscar en las criaturas un reflejo de aquella visión, forzarlas a dar lo que no tienen y quedarse uno al final con la sed viva y el corazón reseco. ¿Entiende? (MARECHAL, 2005, p. 55).

Essa é, portanto, a principal diferença entre o mito barroco de Don Juan e o novo mito romântico, pois este último vai privilegiar apenas o passado e o futuro. Ao tratar da evolução do mito barroco de Don Juan para o mito romântico, Becerra Suárez (1997) enfatiza a importância da influência de Hoffmann, que em sua versão donjuanesca imprime o sonho infinito do herói, ou seja, uma busca incansável pela mulher ideal que o converte em um homem triste e insatisfeito. Do rebelde burlador de Tirso, herói da liberdade absoluta, Don Juan se converte em buscador de um ideal que gera dor e sofrimento, mas que, ao mesmo tempo, desperta o amor e a compaixão de uma das personagens que se destacam do grupo feminino (aqui nos referimos à heroína romântica Inés) abrindo, assim, as portas do perdão e da salvação do libertino:

Inés: ¿Por qué debe irse?

Don Juan: Porque yo doy mala sombra, como dirían sus esquiladores.

Inés: No me importa lo que digan los esquiladores.

Don Juan: Adiós, criatura.

Inés: ¡Adiós! ¿por qué?

Don Juan: Porque un gavilán no anda quieto nunca. Tiene la conciencia demasiado intranquila.

Inés (se le acerca y lo mira en los ojos): - Usted no es un gavilán. Los gavilanes tienen el ojo seco, y usted está llorando señor (MARECHAL, 2005, p. 55).

Essa mudança de perspectiva no tratamento do herói, a partir de Hoffmann e dos escritores românticos ou daqueles que buscam seguir essa nova vertente donjuanesca, não implica necessariamente na eliminação de alguns elementos essenciais da trama, como o grupo de mulheres, o sedutor e o morto. Na releitura de Marechal, por exemplo, Don Juan já é portador de um destino trágico anunciado, desde o início, pelo coro de bruxas, ou seja, ele retorna para expiar suas culpas e encontrar a mulher ideal. Dessa maneira, não atua necessariamente como um sedutor de mulheres, mas é considerado por todos como tal em virtude de suas ações passadas. Também não desaparece o duelo com o pai da heroína Inês e a morte deste pelas mãos de Don Juan. Por outro lado, verifica-se uma retomada dos motivos religiosos que marcaram as versões barrocas, privilegiando diversas facetas místicas do folclore criollo, com uma configuração híbrida que abrange as tradições locais argentinas, de raízes pagãs, e a cultura clássica ocidental e católica.

Ao tratar sobre o mito e a cultura popular no noroeste argentino, Gianuzzi (2012) se refere ao "duende" que golpeia com uma mão de ferro e a outra de lã. É a figura de um 
menino mau que morreu sem ser batizado e que espancou a própria mãe. Geralmente leva um sombreiro grande e chora como criança. Está relacionado a figuras diabólicas oriundas de tradições folclóricas indígenas, como a quéchua.

Em uma notícia de La Gaceta (2015), os duendes argentinos de Tafídel Valle são descritos como criaturas de olhar penetrante e sorriso travesso. Esses seres formam parte da literatura oral e já se converteram em verdadeiras lendas urbanas da cultura do norte argentino. Essa nota de jornal menciona que, em entrevista a Alejandro Urciuolo, diretor do museu "Casa Duende", de Tafí, este defende a ideia de que a lenda dos duendes nasceu como uma peça chave para sustentar o alicerce de um sistema cultural baseado no medo e no castigo, mais propriamente durante a imposição de um sistema religioso: o catolicismo. Acrescenta, ainda, que na cultura celta os duendes não eram representantes do mal, mas seres de boa fortuna, símbolos de sorte. Urciuolo destaca, ainda, que a ideia do ferro como instrumento de castigo foi trazida pelos jesuítas. A relação que se estabelece entre essa criatura folclórica com o contexto violento de colonização parece, de fato, bastante verossímil, pois segundo García Canclini (1982), as culturas populares revelam-se por meio da absorção das ideologias dominantes, denunciando as contradições da própria classe oprimida.

Para Graciela Maturo (2015), há dois grandes temas que perpassam toda a obra de Leopoldo Marechal e que configuram a espinha dorsal desse corpo dramático em análise: a salvação da alma como uma questão pessoal e doutrinária; e a redenção da pátria. Desse modo, chega-se à conclusão, ao retomar os quatro sentidos de interpretação da obra literária propagados nos estudos estético-filosóficos do escritor de Don Juan, que o primeiro deles, o literal, abrange a recriação do mito do sedutor a partir da vertente romântica, na qual o herói da liberdade, de caráter acentuadamente barroco por sua inconstância, cede lugar ao herói que busca incansavelmente o ideal do eterno feminino. Segundo Becerra Suárez (1997), no plano teatral, a vertente romântica recorre à elevação do amor feminino como veículo para instaurar o perdão às atitudes perversas de Don Juan. O primeiro a dar ênfase a essa dimensão foi o francês Molière, ao introduzir a personagem Elvira em sua releitura dramática de 1665, personagem também privilegiada pelo espanhol Antonio de Zamora em No hay plazo que no se cumpla ni deuda que no se pague y Convidado de piedra, obra do século XVII que se converte em um claro precedente da peça romântica de Zorrilla, na opinião do crítico Baquero Goyanes (2005), pois nela já se vislumbra a possibilidade de salvação do burlador a ser contemplada pelo escritor romântico. Elvira corresponde, portanto, a um precedente de Inés da obra de Leopoldo Marechal, que professa um amor indiferente às atitudes que todas as demais personagens condenam em Don Juan. O conto fantástico de Hoffmann (1813) seria, antes da peça de José Zorrilla, de 1844, o primeiro a desmitificar e remitificar o lendário burlador, transformando-o em um homem apaixonado por Ana, uma mulher que, por meio do milagre do amor, está predestinada a regenerá-lo. Na sequência dramática dessa vertente romântica, Leopoldo Marechal filia-se diretamente ao Tenório do espanhol José Zorrilla, de cunho fantástico-religioso.

No que se refere a um segundo sentido interpretativo da peça, de caráter alegórico, é possível dizer que a salvação do herói pelo amor de Inés corresponde ao tema da "redenção nacional" ou "redenção da pátria", que perpassa toda obra de Marechal. A alegoria consiste na relação que se pode estabelecer entre esse tema e a crença no peronismo, alimentada pelo autor, que o concebe como uma doutrina política humanitária de centro, equidistante dos radicalismos do capitalismo e do marxismo. De acordo com 
Alberto Julián Pérez (2014), a Modernidade ganha contornos negativos para o escritor argentino na medida em que contribui para afastar a espiritualidade do centro da vida humana, dessacralizando a arte e submetendo o artista a uma criação voltada para o mercado. Por essa razão, e por sua concepção cristã e nacionalista, Leopoldo Marechal considera o homem contemporâneo como um ser mutilado. Julián Pérez assinala que em 1966 a crítica de Leopoldo Marechal ao liberalismo torna-se ainda mais explícita em seu ensaio publicado em Cuaderno de navegación: "Autopsia de Creso", no qual Creso é o burguês que coloca a questão econômica como central em sua vida. Ao assumir uma veia mística em sua literatura, o autor denuncia, alegoricamente, que o humanismo católico pode servir como remédio à sociedade capitalista e laica, guiada pelo espírito utilitarista, cuja representação na obra recai sobre a figura demoníaca de Don Juan. A redenção final de Don Juan por meio do amor de Inés simboliza a redenção da nação argentina pela via do peronismo católico e profetiza o retorno de Perón, visto que a escritura da obra corresponde a um momento de exílio do ex-presidente e de resistência anti-peronista. $\mathrm{O}$ drama Don Juan parece mesmo profetizar o retorno do líder popular à sua pátria e o enfrentamento de seus opositores, à semelhança do que ocorre com o perverso sedutor que retorna ao povoado de Santa Fé para enfrentar-se com seu passado.

A peça, assim como seu último romance Megafón, o la guerra são anteriores ao retorno do líder popular do exílio e seu triunfo nas eleições de 1973. Leopoldo Marechal morre antes, em 1970. A redenção de Don Juan, pelas mãos de Inés, pode ser lida como uma profecia acerca do tema da redenção da pátria ou da redenção do caudilho, recorrente em toda obra do autor de Adán Buenosayres, visto que Perón também retorna, como Don Juan, para enfrentar-se com seu passado obscuro, ligado à ditadura. Seu êxito nas eleições de 1946 e 1973 se deve, sobretudo, à forte campanha nacionalista e humanitária que teve como protagonista e mediadora uma mulher, convertida em mito: Eva Perón ou "Santa Evita". O drama Don Juan apresenta, desde suas primeiras linhas, um plano de salvação para o libertino. Para isso é necessário, contudo, que o sedutor passe por um sacrifício de sangue, única via possível para o encontro com o espírito santo - simbolizado por Ayme, a mulher designada na obra de "paloma", quem o conduzirá ao caminho da purgação de seus pecados. Impregnada de uma teologia mística, a escritura em análise atribui a Aymé o mesmo papel de João Batista, aquele que prepara os caminhos para a vinda do grande messias. Aymé o conduz pela via purgativa do "descenso", da "Salamanca infernal", para que, por meio de Inés, ele possa encontrar a via iluminativa do "ascenso".

O simbolismo da figueira, enfatizado na obra, em conexão com Inés, a intercessora, torna-se a via transcendente que elevará Don Juan ao cristianismo. A figueira é, nos textos bíblicos, uma alusão bíblica a Israel e contém um profundo sentido profético que remete aos desígnios da salvação. À tragédia de Don Juan, anunciada pelos habitantes do povoado, se opõe a convicção de sua redenção, revelada por meio dos símbolos cristãos de transformação: a festa de São João, a figueira e o rio; este último representando as águas batismais. Essa conotação corresponde ao terceiro nível interpretativo da obra, fundamentado em sua dimensão moralizante, na qual a literatura mística do autor pode ser comparada ao evangelho levado aos gentios e que culmina em seu quarto sentido, o anagógico, ou a religação do homem moderno e mutilado com a espiritualidade, colocada à margem nas sociedades modernas. 


\section{REFERÊNCIAS}

(S. A.) Los duendes cachetean con mano de hierro o mano de lana. La Gaceta. Tucumán, 20 febrero, 2015. Disponível em: $<$ http://www.lagaceta.com.ar/nota/627496/sociedad/duendes-cachetean-mano-hierro-omano-lana.htm>. Acesso em: 10 mai. 2016.

BACHELARD, G. A poética do espaço. São Paulo: Abril Cultural, 1978.

BAQUERO GOYANES, A. Don Juan siempre Don Juan (Todos los Tenorios del teatro español). Madrid: Fundación Premios Mayte, 2005.

BECERRA SUÁREZ, C. Mito y Literatura (Estudio comparado de Don Juan). Vigo: Universidad de Vigo, 1997.

ELIADE, M. Imagens e Símbolos. Tradução de Maria Adozinda Oliveira Soares. Lisboa: Arcádia, 1979.

GARCÍA CANCLINI, N. Las culturas populares en el capitalismo. Buenos AiresArgentina: Nueva Imagen, 1982.

GIANUZZI, E. El miedo en la "otredad": mito y cultura popular en el noroeste argentino. Cuadernos Interculturales. Viña del Mar/Chile, v. 10, n. 18, p. 77-111, 2012.

JULIÁN PÉREZ, A. Marechal, Megafón y la Resistencia Peronista. Revista Destiempos, n. 42 , p. 87-104, dic. 2014.

LOJO, M. R. El Símbolo: poéticas, teorias, metatextos. México: Universidad Nacional Autónoma de México, 1997.

MARECHAL, L. Don Juan. Buenos Aires: Colihue, 2005.

MATURO, G. Leopoldo Marechal, el caminho de la beleza. Buenos Aires: Biblos, 1999.

. Leopoldo Marechal y el destino de la Argentina, 25 de mayo de 2015. Disponível em: <https://epanadiplosis.wordpress.com/2015/05/24/leopoldo-marechal-yel-destino-de-la-argentina-por-graciela-maturo/>. Acesso em: 10 mai. 2016.

ROUSSET, J. El mito de Don Juan. Traducción de Juan José Utrilla. México: Fondo de Cultura Económica, 1985.

RUBIONE, A. Introducción, notas y propuestas de trabajo. In: MARECHAL, L. Don Juan. Buenos Aires: Colihue, 2005. p. 23-35.

SECCHI, V. E. Leopoldo Marechal: una estética unitiva: estudio de la recepción de fuentes griegas y cristianas. Córdoba: Universidad Nacional de Córdoba, 2014.

Recebido em: 17/10/2016

Aprovado em: 29/11/2016 